\title{
Comparative Analysis of the Amount of Biogas Produced by Different Cultures using the Modified Gompertz Model and Logistic Model
}

\author{
Srigan Moharir ${ }^{1 \star}$, Ameya Bondre ${ }^{1}$, Salil Vaidya ${ }^{1}$, Parth Patankar ${ }^{1}$, Yashraj Kanaskar ${ }^{1}$, Hemlata Karne ${ }^{1}$
}

${ }^{1}$ Vishwakarma Institute of Technology, Pune, INDIA

*Corresponding Author: srigan.moharir17@vit.edu

Citation: Moharir, S., Bondre, A., Vaidya, S., Patankar, P., Kanaskar, Y. and Karne, H. (2020). Comparative Analysis of the Amount of Biogas Produced by Different Cultures using the Modified Gompertz Model and Logistic Model. European Journal of Sustainable Development Research, 4(4), em0141. https://doi.org/10.29333/ejosdr/8550

ARTICLE INFO

Received: 14 Jul. 2020

Accepted: 10 Aug. 2020

\begin{abstract}
With the increase in population, the amount of food waste generated is increasing exponentially. Anaerobic digestion can serve the purpose of managing organic waste in an eco-friendly way. Microorganisms play a vital role in the process of anaerobic digestion. In this work, the effect of anaerobic digestion was analyzed using two organic cultures- Cow Dung and Horse waste which was in turn compared to an Industrial Culture with regards to the biogas produced over a cycle of 14 days. Between the two organic cultures, the volume of biogas produced by Horse waste was $35,366.03 \mathrm{~cm}^{3}$ which compared to the biogas produced by cow dung was considerably large. The use of Horse waste as potential biomass has the capacity to produce biogas which can be utilized as a biofuel. The experimental data were evaluated using mathematical models like the Modified Gompertz Model, Logistic Model, and First Order Kinetics Model. Of the three models used, Modified Gompertz Model and Logistic Model gave a good fit for the experimental data with 0.98 and 0.97 respectively as the Coefficient of Determination $\left(R^{2}\right)$. While the First Order Kinetics Model underperformed with an $\mathrm{R}^{2}$ value of 0.68 . The Modified Gompertz gave accurate results which thus validated the experimental data.
\end{abstract}

Keywords: anaerobic digestion, biogas, food waste, horse waste, Gompertz Model, logistics function

\section{INTRODUCTION}

With an exorbitant increase in the per capita energy consumption, our dependence on renewable and cheap modes of energy has increased. Enhancing resources like biogas is necessary with regard to its ability to act as a clean alternative to fossil fuels. And in turn the production of green energy significantly contributes to sustainable development and reduction in greenhouse gas emissions and global warming. The problem of finding cheaper and cleaner alternative sources of energy is further compounded by poor waste disposal and management systems in parts of the developing world.

For the utilization of biomass, processes like anaerobic digestion have proven to be efficient and in turn, helps in managing waste. The waste majorly consists of food waste which can be found at the domestic level. Thus, the generation of biogas provides an excellent solution to solve both these issues utilizing decomposing organic waste, particularly by the degradation of animal waste which may pose a threat to public health, to produce a cleaner form of energy (Kumar et al., 2017; Manyi-Loh et al., 2013) Since the last decade, major developments in the field of bioenergy have been observed. Advancements in molecular biology have provided researchers with a better understanding of complex microbiological systems. Improved reactor designs and mathematical models have optimized the production of biogas. (Horváth et al., 2016).

Anaerobic decomposition of organic waste makes use of bacteria to produce biogas, which largely constitutes the mixture of methane $\left(\mathrm{CH}_{4}\right)$ and carbon dioxide $\left(\mathrm{CO}_{2}\right)$ gases. The combustible nature of biogas makes it a practicable alternative source of energy used for cooking, heating, lighting, etc. (Chakravarthi, 1997). Biogas production by anaerobic digestion can be explained by four successive phases- Hydrolysis, Acidogenesis, Acetogenesis, and Methanogenesis (Figure 1). In Hydrolysis, complex polymers are broken down into simpler ones, simpler sugars from Carbohydrates, Amino Acids from Proteins, and fatty acids from lipids are some notable examples. Acidogenesis involves the formation of short-chain organic acids by the breakdown of monomers. In view of the previous step, acetic acid is formed by converting the organic acids (formed in the process of Acidogenesis). The oxygen dissolved is consumed by acetogenic bacteria from the slurry which in turn is responsible for creating an anaerobic environment, known as the acetogenesis phase. This gas contains large proportions of carbon dioxide, as the methanogenic bacteria are still inactive in the presence of the aerobic conditions within the digester, containing trapped air (Okonkwo et al., 2018). Finally, the methanogenic bacteria perform the function of converting acetic acid to methane and carbon dioxide under anaerobic conditions (Anukam et al., 2019). 


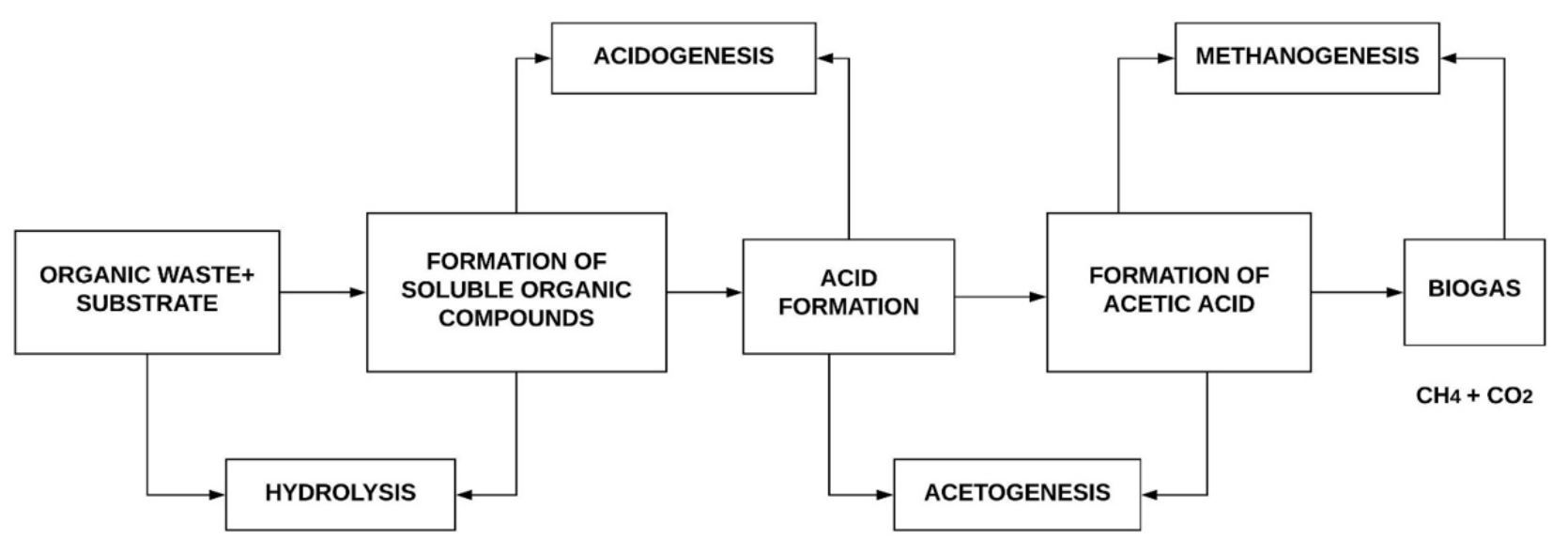

Figure 1. Phases of Anaerobic Digestion

The main parameters which affect biogas production are temperature, $\mathrm{pH}$, hydraulic retention time, substrate, and culture. Animal manure which is rich in carbon and nitrogen is used as organic fertilizer and as cooking fuel in the form of dung cakes/pellets as a source of energy. Having high nutritive and calorific values, organic waste material like cow dung and horse waste can be used to efficiently produce methane which is a utilizable form of energy (Caruso et al., 2019).

Livestock manure contains a variety of bacteria that play a key role in the generation of biogas under ambient conditions. Cow dung, in particular, has been studied as a source to produce biogas under anaerobic conditions (Awasthi et al., 2018; Mel et al., 2015). Horse waste has been widely used as a substitute for cattle dung as a source of biogas production (Kalia and Singh, 1998; Kusch et al., 2008). Some cultures and strains of bacteria have been artificially enhanced using those found in the natural world, to improve the activity of bacteria and subsequent biogas yield (Jain et al., 2014). It is necessary to understand and/or quantify the biogas productivity of the organic waste cultures in comparison to the synthetically developed cultures. Thus, aiding in the choice of a culture feasible for small scale operations.

Employing various Kinetic Models, the biogas potential for a system can be predicted, such a study to determine the Biochemical Methane Potential (BMP) is key to understand the feasibility of using a certain kind of substrate to produce desired amounts of biogas (Gerber and Span, 2008; Strömberg et al., 2014; Ware and Power, 2017). Such studies are also helpful to design scale up operations, especially for larger digester units intended to produce biogas using the selected substrates by means of certain parameters like the lag phase $(\lambda)$ and biogas production potential (P).

This study aims to compare the biogas productivity of two such organic waste cultures- Cow Dung (CD) and Horse Waste (HW) in comparison to an Industrial Culture (IC), over a model food waste. The objective of the study is to determine if either one or both of the organic waste cultures can yield a sufficient amount of biogas like the industrially developed Industrial Culture (IC). The specific interest in organic wastes is to determine which of the two organic wastes (HW or CD) is viable for small scale or household biogas production. The study also specifically aims to determine the best fitting kinetic model for the experimental biogas data collected for all three cultures.

\section{MATERIAL AND METHODS}

\section{Culture Collection}

The IC was obtained from a digester working on food waste, from Thyssenkrupp India Pvt. Ltd. facility in Pimpri-Chinchwad, Maharashtra, India. The fresh HW was obtained from a stable in Sahakar Nagar, Pune, India whereas fresh CD was procured from a cow pen in Kondwa, Pune.

\section{Experimental Apparatus Set-up}

The use of floating drum digesters (10 litres) had been used in this work for biogas production. The complete apparatus consisted of a 10-litre drum, 7-litre drum, elbow bend, a valve, a nozzle, and a measuring tape. A hole was drilled on the 7-litre inverted drum and a mechanical combination of valve and nozzle were attached to it. The measuring tape was employed to check the level of the gas generated (Figure 2). The placement of the 7-litre drum on the 10-litre drum was such that it created a vacuum and all the air was released through the nozzle. Care was taken that the inverted drum did not fit tight which might have otherwise opposed the pressure exerted by the formation of biogas. 


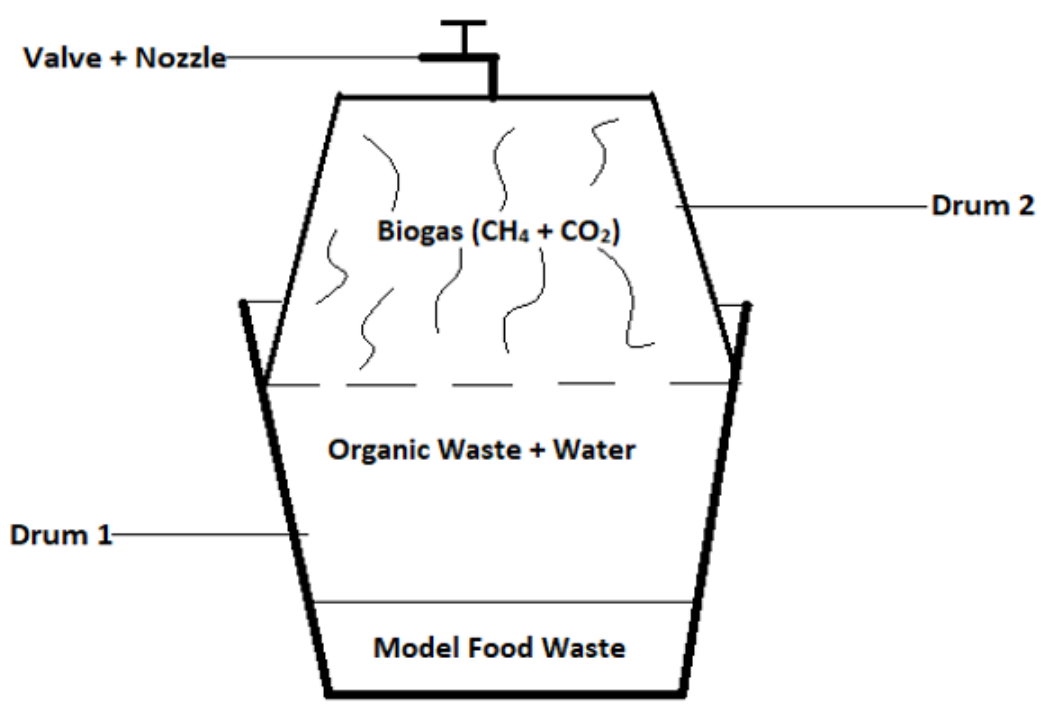

Figure 2. Schematic of a Floating Drum Digester

\section{Experimental Design}

The following constituents were added to the apparatus (Figure 2). $1 \mathrm{~kg}$ of soybean substrate used as the model food waste was added to $1 \mathrm{~kg} C D$. In addition to this, $15 \mathrm{~g}$ of ammonium chloride was added to maintain the C: $\mathrm{N}$ ratio. The entire mixture was then diluted with water up to the 10-litre mark. A similar approach was used for HW culture and the IC. The experimental runs were carried out in batch mode.

\section{Experimental Procedure}

Once the digester was set up with the constituent mixture, the amount of gas produced was measured by the height corresponding to the layer of gas generated which was matched with the measuring tape. A cycle of 21 days was carried out initially for $C D$ but since there was a negligible amount of biogas being generated after 14 days, hence further runs were taken for 14 days. The amount of biogas generated was recorded and tabulated. A similar approach was used for HW and the IC. Figure 3 summarizes the method used during the research.

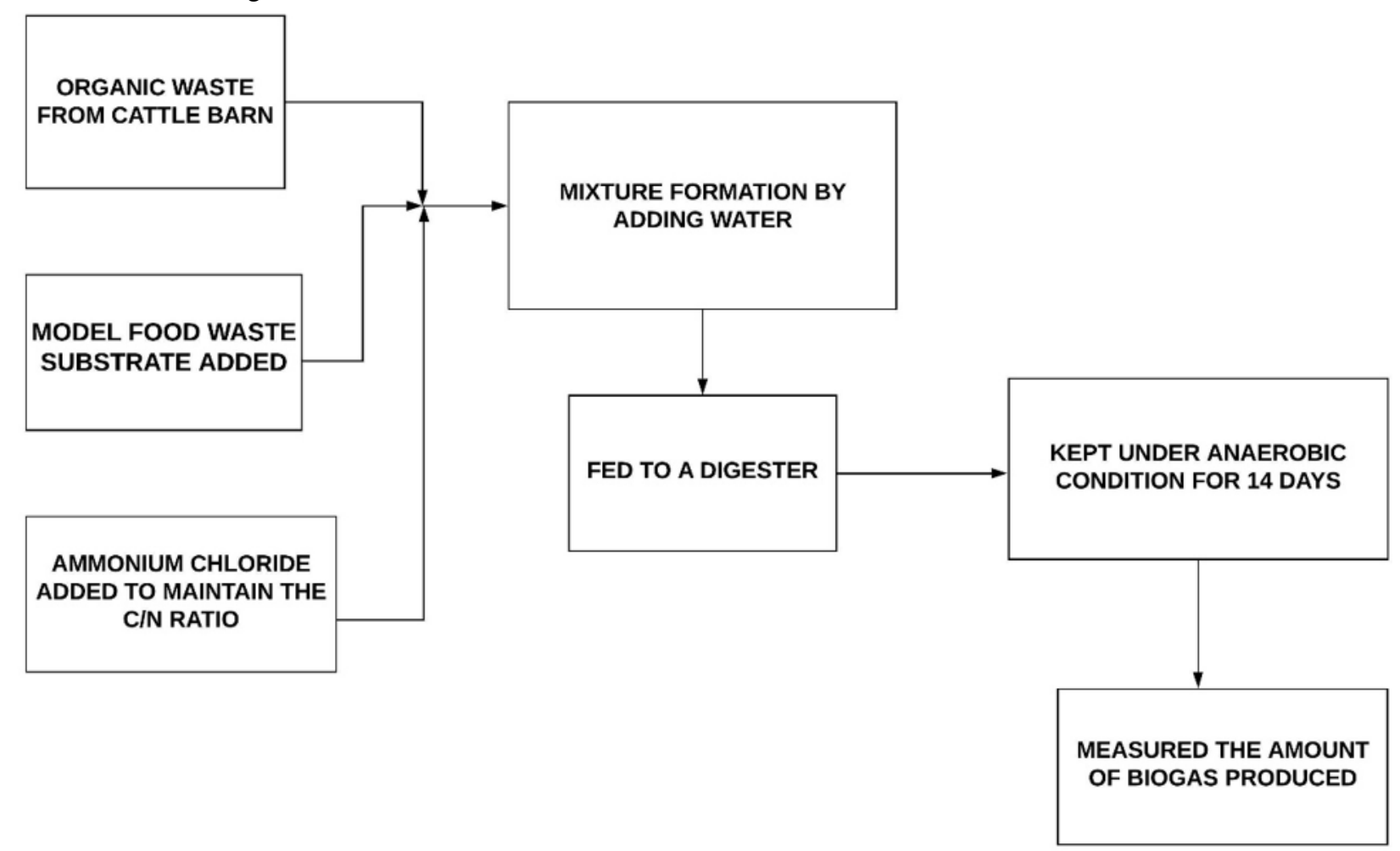

Figure 3. Flow diagram of the process undertaken for Biogas production and measurement

Measurement of the amount of Biogas generated was carried out by obtaining the volume of the frustum whose bigger end would vary depending upon the amount of gas collected on any particular day. The temperature and pH were monitored regularly.

The volume of gas collected $=$ Volume of Frustum 


$$
V=\frac{1}{3} * H *\left(R_{1}^{2}+R_{2}^{2}+R_{1} R_{2}\right)
$$

Where,

$\mathrm{V}=$ Volume

$\mathrm{H}=$ Height of the Frustum

$\mathrm{R}_{1}=$ Radius of Bigger End

$\mathrm{R}_{2}=$ Radius of Smaller End

\section{Kinetic Models for Biogas Yield Production}

The following models were fitted to the cumulative biogas production data obtained from the experiments. This allows for the evaluation of the various parameters associated with each model. These parameters aid the comparative study of the biogas yield from different cultures in a quantitative manner.

\section{First Order Kinetic Model}

The simplest and the crudest estimation kinetic model for biogas production can be done with the help of first-order kinetics. Some researchers have explained the use of first-order kinetics by assuming the Hydrolysis step in the degradation of feed mixture as the rate-limiting step (Parameswaran and Rittmann, 2012; Pavlostathis and Giraldo-Gomez, 1991).

$$
M=P .\{1-\exp [K * t]\}
$$

M: cumulative biogas production $\left(\mathrm{cm}^{3}\right)$

$\mathrm{t}$ : duration at which cumulative biogas production $\mathrm{M}$ is calculated (day)

$\mathrm{P}$ : biogas production potential $\left(\mathrm{cm}^{3}\right)$

$\mathrm{K}$ : Biogas rate constant $\left(\right.$ day $\left.^{-1}\right)$

\section{Logistics Model}

The Logistic Model depicts a sigmoid curve. It is a growth curve widely used for modelling and predictive purposes. It essentially helps predict the initial exponential rise and subsequent stabilization at maximum production levels, assuming the rate of biogas produced is proportional to the amount of biogas previously produced (Donoso-Bravo et al., 2010; Pramanik et al., 2019).

The function is as follows:

$$
M=\frac{P}{\left\{1+\exp \left[4 * R m * \frac{(\lambda-t)}{P}+2\right]\right\}}
$$

M: cumulative biogas production $\left(\mathrm{cm}^{3}\right)$

$\mathrm{t}$ : duration at which cumulative biogas production $\mathrm{M}$ is calculated (day)

P: biogas production potential $\left(\mathrm{cm}^{3}\right)$

$\mathrm{Rm}$ : maximum biogas production rate $\left(\mathrm{cm}^{3} /\right.$ day)

$\lambda$ : duration of lag phase (day)

\section{Modified Gompertz Model}

The reparameterization of the Gompertz equation was done in 1990 and came to be known as the 'Modified Gompertz Equation/Model' (Tjørve and Tjørve, 2017; Zwietering et al., 1990). It is a multi-parameter (three-parameter), sigmoid growth model. This model is commonly used in biology to model the growth of micro-organisms, the growth of animals, etc. The modified Gompertz equation is used to model the kinetic data of biogas experiments by assuming that the biogas produced in the batch condition corresponds to the growth rate of methanogenic bacteria in the biodigester. The equation is:

$$
M=P \cdot \exp \left\{-\exp \left[\frac{R m \cdot e}{P}(\lambda-t)+1\right]\right\}
$$

M: cumulative biogas production $\left(\mathrm{cm}^{3}\right)$

$\mathrm{t}$ : duration at which cumulative biogas production $\mathrm{M}$ is calculated (day)

$\mathrm{P}$ : biogas production potential $\left(\mathrm{cm}^{3}\right)$

$\mathrm{R}_{\mathrm{m}}$ : maximum biogas production rate $\left(\mathrm{cm}^{3} /\right.$ day)

$\lambda$ : duration of lag phase (day)

The parameters of this model are $R_{m}, P, \lambda$. The higher the value of ' $R_{m}$ ' the higher the production rate of biogas and $\lambda$ is essential to determine the efficiency of anaerobic digestion (Li et al., 2019). 


\section{RESULTS AND DISCUSSION}

Biogas was produced at mesophilic conditions $\left(25-40^{\circ} \mathrm{C}\right)$ throughout the duration of the fourteen-day cycle. The digester was kept at ambient conditions because it was easy to maintain and not very sensitive to temperature fluctuations, as the external temperature conditions of the location remained in the aforementioned temperature range. The $\mathrm{pH}$ of the system was 7 . The digester was also more stable at mesophilic conditions than at thermophilic conditions (Nges and Liu, 2010). The amount of biogas collected for the three different cultures was noted daily for 14 days. The gas was analyzed using gas chromatography- the IC, HW, and CD cultures contained $72 \%, 68-70 \%$, and $63 \%$ methane content respectively. The gas analysis was carried out in Horizon Services, Pune, India. Runs were repeated for confirmation of results. The experimental data on the three cultures were then fitted into kinetic models namely First Order Kinetic Model, Logistic Model, and Modified Gompertz Model and the results were analyzed to identify the most suitable model that can be used to predict the amount of biogas generated.

Table 1 and Figure 4 represent the cumulative amount of biogas produced after completing a 14-day cycle under anaerobic conditions. The data indicate that IC had higher biogas production daily than the other 2 cultures with a total biogas production of $48004.97 \mathrm{~cm}^{3}$. The superior performance of the IC can be attributed to the fact that it was developed for industrial use. The CD produced the lowest biogas among the three cultures with a total biogas production of $9188.03 \mathrm{~cm}^{3}$. HW culture performed better than CD but produces $26 \%$ less biogas than IC with a total biogas production of $35366.03 \mathrm{~cm}^{3}$. The data also shows that the CD takes more time to activate and also produces comparatively less biogas. While IC and HW cultures take less time to activate.

$\mathrm{HW}$ culture gives its best performance during the first half of these 14 days. It is also observed that unlike the other two cultures, the HW culture produces a significant amount of biogas over an 11-day cycle, and then there is no further production of biogas (Table 1, Figure 4). As HW yields higher biogas productivity than CD, it may be suitable for household or small-scale digester use. Also, the CD culture is largely inactive - a spell of nearly 7 days of inactivity is followed by peak biogas production on Day 9 and then again results in meagre amounts of biogas production post Day 11 . Unlike the two Organic Cultures which produce insignificant amounts of biogas in the later stages, the IC produces feasible amounts of biogas until the cycle concludes on Day 14 (Figure 4).

Table 1. Cumulative Amount of Biogas Produced

\begin{tabular}{cccc}
\hline Time & Industrial Culture $\left(\mathbf{c m}^{\mathbf{3}}\right)$ & Cow Dung $\left(\mathbf{c m}^{\mathbf{3}}\right)$ & Horse Waste $(\mathbf{c m})$ \\
\hline Day 1 & 13845.76 & 3758.95 & 6823.81 \\
\hline Day 2 & 18885.21 & 3758.95 & 7616.05 \\
\hline Day 3 & 23311.58 & 3758.95 & 12042.41 \\
\hline Day 4 & 27737.94 & 3758.95 & 19346.21 \\
\hline Day 5 & 30711.54 & 3758.95 & 23772.58 \\
\hline Day 6 & 33685.14 & 3758.95 & 25838.43 \\
\hline Day 7 & 36198.89 & 3952.80 & 37043.68 \\
\hline Day 8 & 36589.43 & 3952.80 & 30017.28 \\
\hline Day 9 & 38219.17 & 7398.35 & 32531.04 \\
\hline Day 10 & 39424.43 & 8603.60 & 373736.29 \\
\hline Day 11 & 40629.68 & 8797.49 \\
\hline Day 12 & 40629.68 & 8797.49 \\
\hline Day 13 & 44559.43 & 9188.03 \\
\hline Day 14 & 48004.97 & & 35366.03 \\
\hline
\end{tabular}

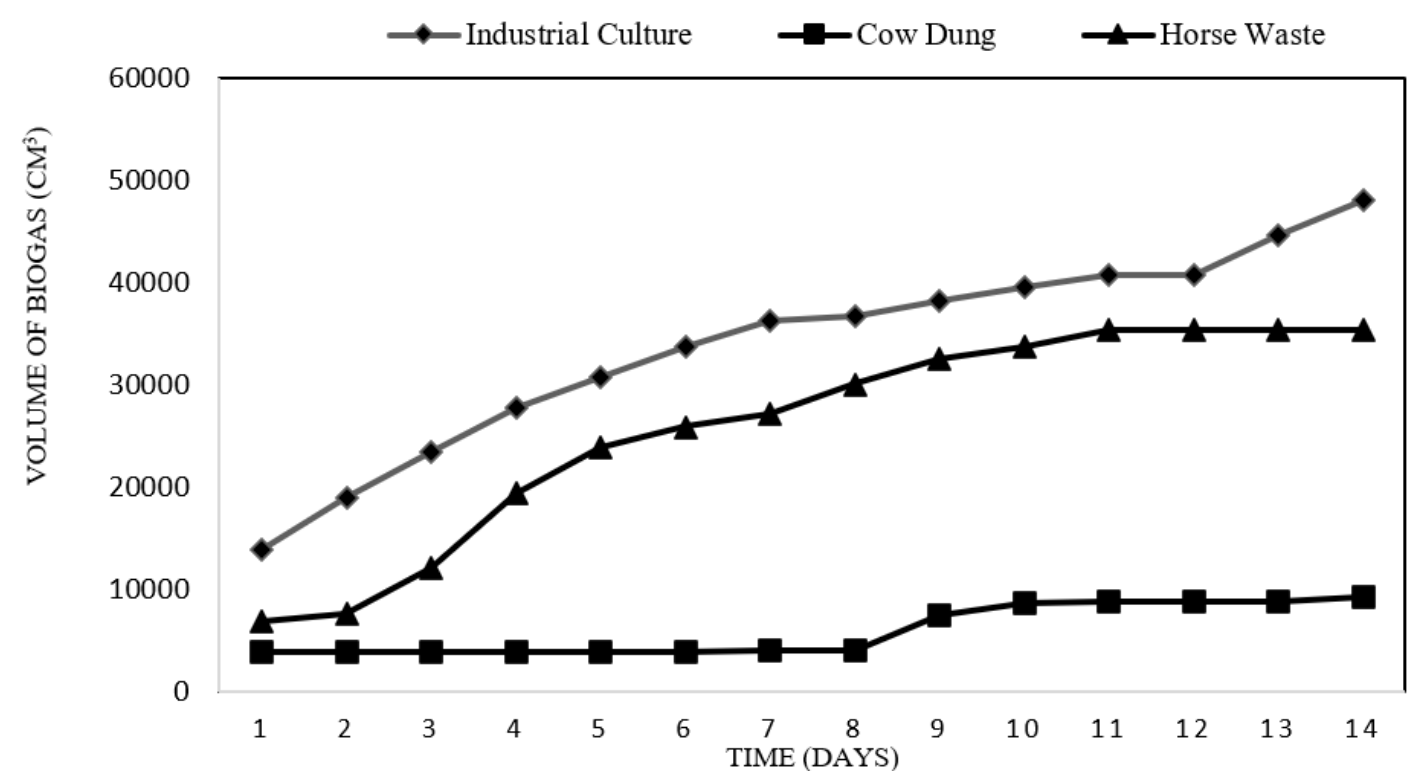

Figure 4. Amount of Biogas Produced 


\section{First Order Kinetic Model}

Figure 5 and Table 2 represent the plot and optimized data for the First order Kinetic Model after fitting the equation for the predictive model. The Coefficient of Determination $\left(R^{2}\right)$ values which represent how well a model fits the data are 0.95 and 0.98 for $\mathrm{IC}$ and HW cultures which shows that the model curve fits the experimental data accurately but in the case of cow dung, the $\mathrm{R}^{2}$ value is 0.69 which is abysmally low and is not satisfactorily accurate. The rate constant (K) values for IC, CD, and HW cultures are approximately 0.24 day $^{-1}, 0.05$ day $^{-1}$, and 0.15 day $^{-1}$, respectively.

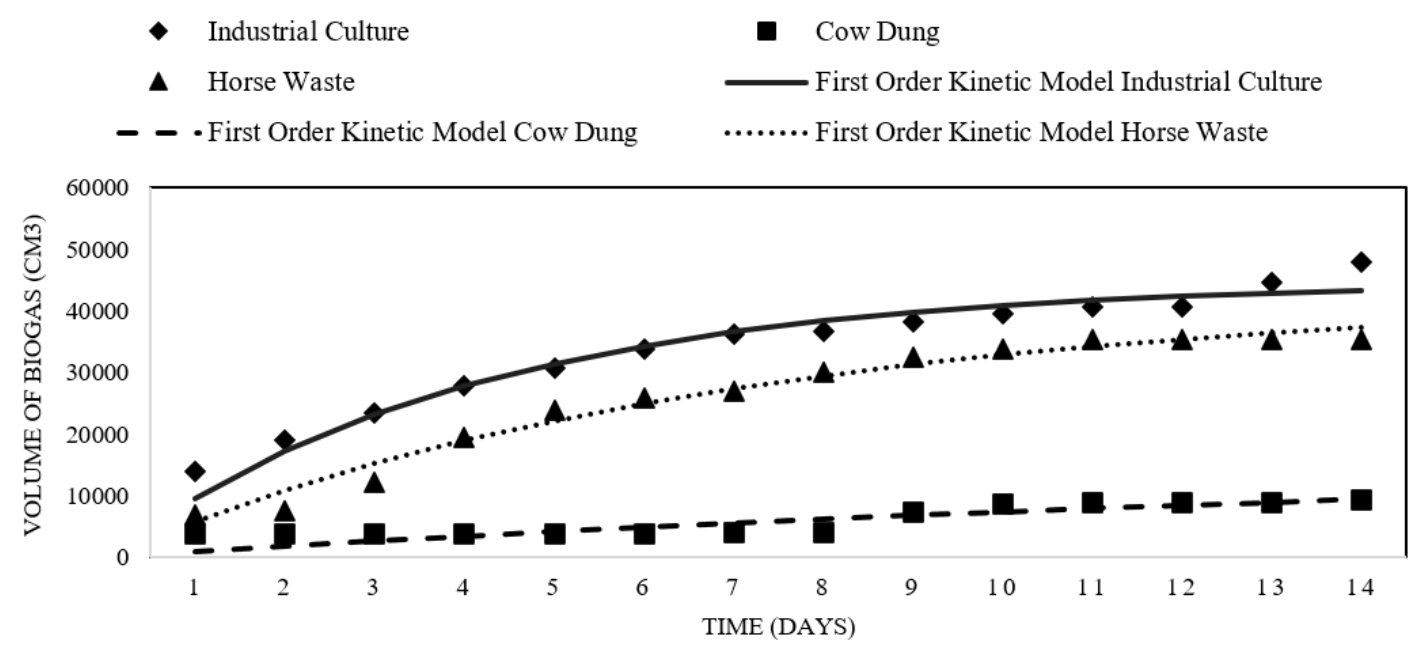

Figure 5. Graph for First Order Kinetic Model

Table 2. Optimized Data for First Order Kinetic Model

\begin{tabular}{ccccc}
\hline & $\mathbf{P}\left(\mathbf{c m}^{\mathbf{3}}\right)$ & $\mathbf{K}\left(\right.$ day $\left.^{-1}\right)$ & $\mathbf{R}^{\mathbf{2}}$ & Variance \\
\hline IC & $4.48^{\star} 10^{4}$ & 0.24 & 0.95 & $4.85^{\star} 10^{6}$ \\
\hline CD & $1.79^{\star} 10^{4}$ & 0.05 & 0.68 & $2.09^{\star} 10^{6}$ \\
\hline HW & $4.28^{\star} 10^{4}$ & 0.15 & 0.97 & $2.78^{\star} 10^{6}$ \\
\hline
\end{tabular}

\section{Logistic Model}

Figure 6 and Table 3 represent the plot and optimized data for the Logistics Model after fitting the equation for the predictive model. The Coefficient of Determination $\left(R^{2}\right)$ is 0.97 and 0.99 for IC and HW which shows that the model curve fits the experimental data accurately and in the case of $C D$, the $R^{2}$ value is 0.83 indicating poor curve fit for the given data. The lag phase ( $\lambda$ ) predictions for the IC, CD, and HW cultures are 2.98 days, 2.17 days, and 4.06 days respectively but are not close to the actual experimental observations.

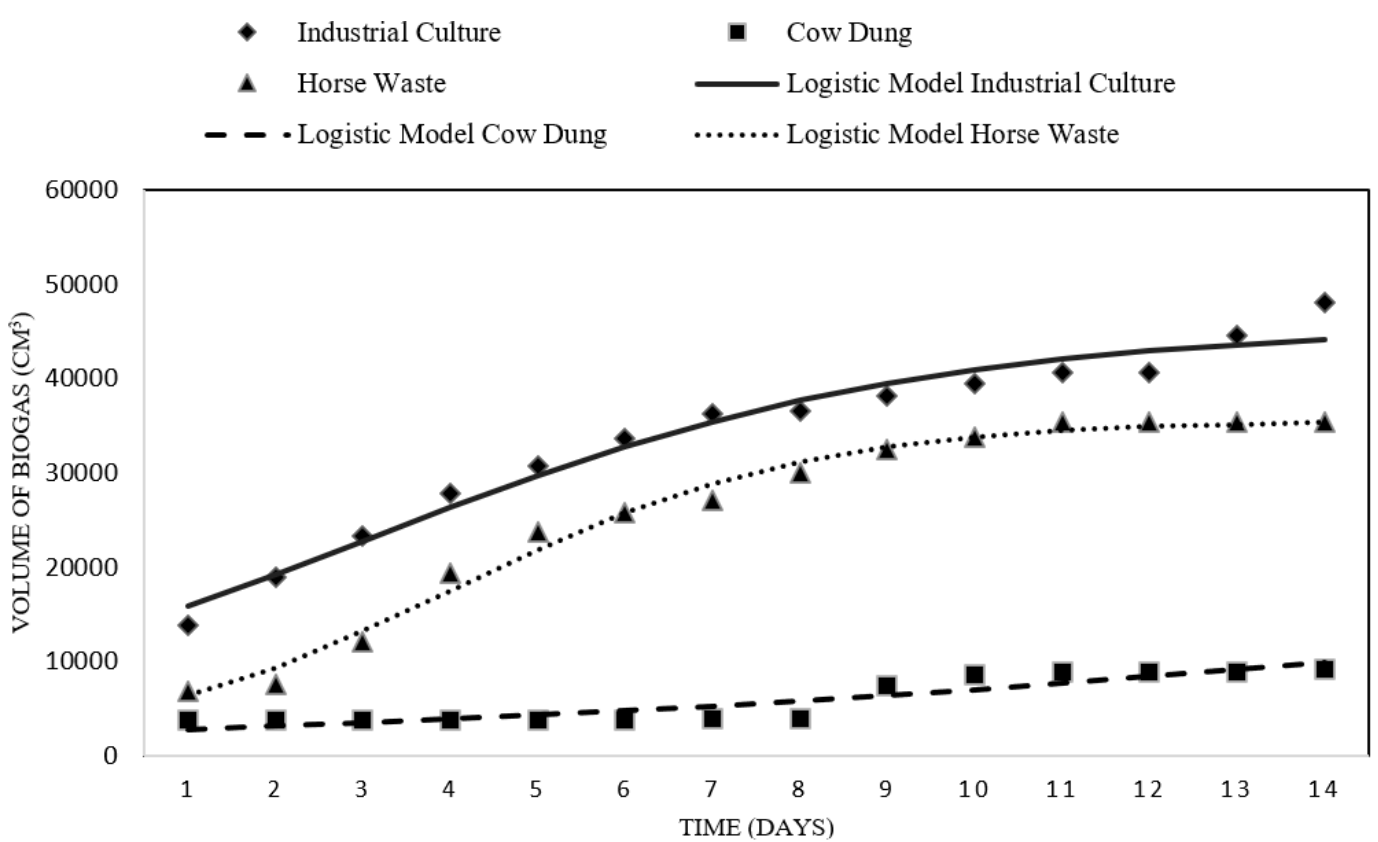

Figure 6. Graph for Logistic Model 
Table 3. Optimized Data for Logistic Model

\begin{tabular}{|c|c|c|c|c|c|}
\hline & $P\left(\mathrm{~cm}^{3}\right)$ & $\mathrm{Rm}\left(\mathrm{cm}^{3} /\right.$ day $)$ & $\lambda$ (days) & $\mathbf{R}^{2}$ & Variance \\
\hline IC & $4.54^{\star} 10^{4}$ & 3586.38 & 2.98 & 0.97 & $3.44^{\star} 10^{6}$ \\
\hline$C D$ & $2.65^{\star} 10^{4}$ & 830.317 & 2.17 & 0.83 & $1.22^{\star} 10^{6}$ \\
\hline $\mathrm{HW}$ & $3.56^{\star} 10^{4}$ & 4438.09 & 4.06 & 0.99 & $1.59^{\star} 10^{6}$ \\
\hline
\end{tabular}

\section{Modified Gompertz Model}

Figure 7 and Table 4 represent the plot and optimized data for the Modified Gompertz Model after fitting the equation for the predictive model. The lag phase $(\lambda)$ predictions for the IC, CD, and HW cultures are $0,8.26$, and 0.05 days respectively which are closer to the actual experimental observations. The Coefficient of Determination $\left(R^{2}\right)$ is 0.98 and 0.99 for IC and HW cultures which shows that the model curve fits the experimental data accurately and in the case of $C D$, the $R^{2}$ value is 0.83 indicating poor curve fit for the data.

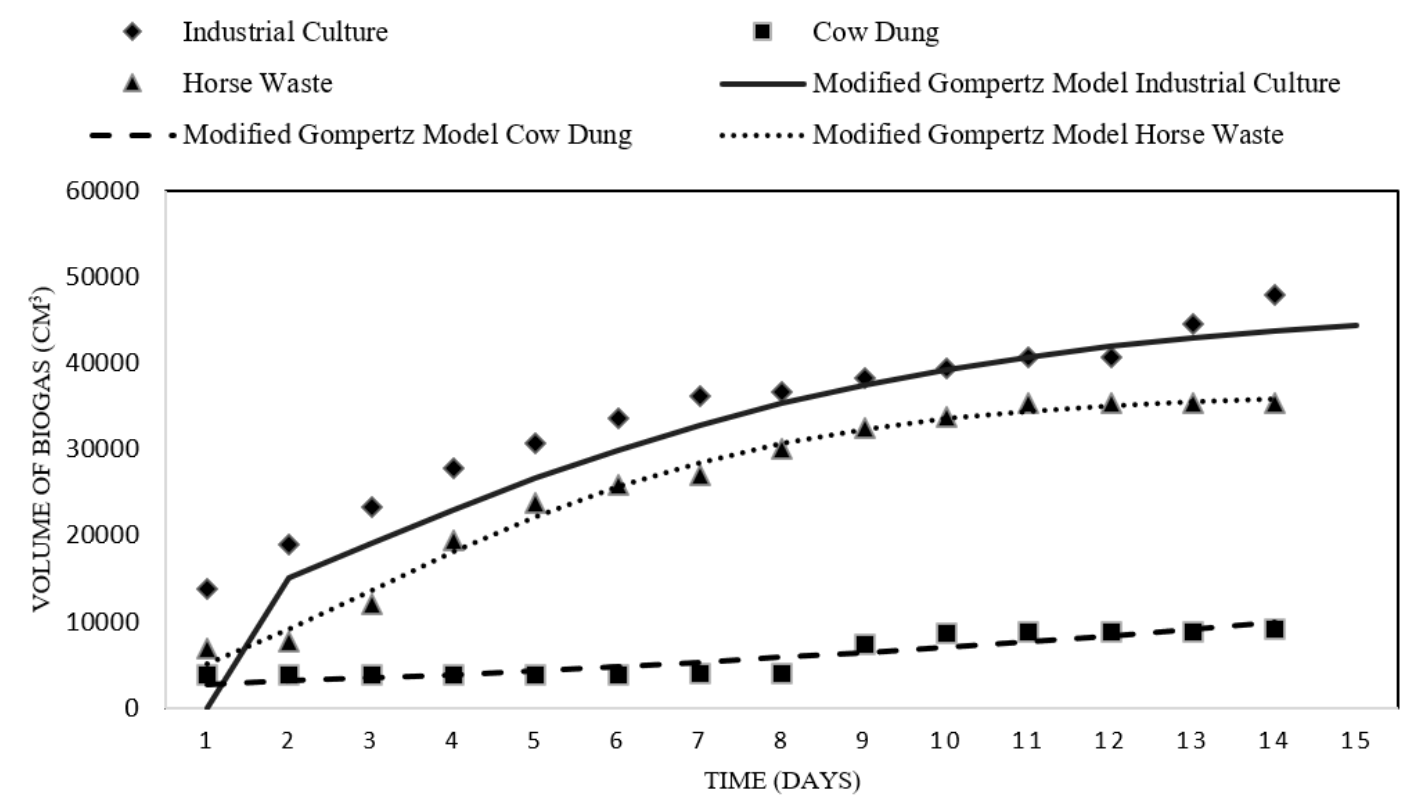

Figure 7. Graph for Modified Gompertz Model

Table 4. Optimized Data for Modified Gompertz Model

\begin{tabular}{cccccc}
\hline & $\mathbf{P}\left(\mathbf{c m}^{\mathbf{3}}\right)$ & $\mathbf{R m}\left(\mathbf{c m}^{\mathbf{3}} / \mathbf{d a y}\right)$ & $\boldsymbol{\lambda}$ (days) & $\mathbf{R}^{\mathbf{2}}$ & 0.98 \\
\hline $\mathrm{IC}$ & $4.71^{\star} 10^{4}$ & 3979.69 & 0 & $2.68^{\star} 10^{6}$ \\
\hline $\mathrm{CD}$ & $9.09^{\star} 10^{4}$ & 1173.02 & 8.26 & 0.83 \\
\hline $\mathrm{HW}$ & $3.68^{\star} 10^{4}$ & 4611.99 & 0.05 & $1.25^{\star} 10^{6}$ & 0.99 \\
\hline
\end{tabular}

Comparison of Biogas Production Using Three Different Cultures

Overall, the performance of the three cultures over the model food waste indicates that IC gives higher biogas yield as compared to HW. This can be attributed to the fact the culture contains activated Hydrolytic, Acetogenic, Acidogenic, and Methanogenic bacteria in it, unlike HW where the bacteria activate naturally as the reaction proceeds over time. Both the mixtures outperform the $C D$ culture, this can be reasoned particularly by the higher average $C: N$ ratio present in HW as compared to CD, 30 and 19 on weight by weight basis respectively, and its higher methane production potential (Äüôú 2003; Cucui et al., 2018). A high C:N ratio of 25 to 30:1 is suitable for the effective digestibility of dairy manure and field crop residuals (Ghatak and Mahanta, 2014; Hills and Roberts, 1981). IC has a considerably higher variance in comparison to the two other animal waste cultures, indicating a greater spread of predicted values from the mean biogas production value, and is observed in all three predictive Kinetic Models (Tables 2-4).

\section{Comparison of Kinetic Models}

The biogas production potential $(\mathrm{P})$ was nearly equal for all three models when used for the IC, all values were in the range of $4500 \mathrm{~cm}^{3}$. The value of $\mathrm{P}$ was around $3550 \mathrm{~cm}^{3}$ for the HW culture using Modified Gompertz and Logistic Model, but a considerably higher value was observed $4280 \mathrm{~cm}^{3}$ in the case of the First Order Kinetic Model for the same. However, all three models produced a variation in the value of $P$ when used to predict the least productive $C D$ culture- $1790 \mathrm{~cm}^{3}, 2650 \mathrm{~cm}^{3}$, and $9090 \mathrm{~cm}^{3}$ for First Order Kinetic, Logistic and Modified Gompertz Model respectively (Tables 2-4).

The maximum biogas production rate $(\mathrm{Rm})$ values predicted for the same cultures using both Logistic and Modified Gompertz Model were similar except for CD which gave $830.317 \mathrm{~cm}^{3} /$ day using the Logistic Model and $1173.018 \mathrm{~cm}^{3} / \mathrm{day}_{\text {using Modified }}$ Gompertz Model. 
The lag phase $(\lambda)$ predictions by the Modified Gompertz Model were closer to the actual experimental observations than those values predicted using the Logistic Model, wherein the IC and HW cultures were nearly spontaneous to produce biogas, but the CD culture was rather slow to activate after an initial quantity of biogas generation (Figures 6, 7). The latter predicted a lag phase of 2.98 days, 2.17, and 4.06 days whereas the Modified Gompertz Model predicted lag phases of 0, 8.26, and 0.05 days for the IC, CD, and HW cultures respectively (Tables 3,4).

In terms of the Coefficient of Determination $\left(R^{2}\right)$, which is an indicator of how best the predictive model curve fits the experimental observations (Figures 5-7). Although the three models have desirably high values of $\mathrm{R}^{2}$, at least 0.95 for HW and IC, the predictive model curves of Logistic Function and Modified Gompertz Model fit slightly better than the First Order Kinetic. On the other hand, the Coefficients of determination for CD culture are poor- $0.69,0.83,0.83$ for First Order Kinetics, Modified Gompertz, and Logistic Model respectively

\section{Error Analysis}

Error analysis was done as a measure to determine the accuracy of the Kinetic Models used to predict the biogas generation.

Error $=($ Mexperimental- Mpredicted $) /$ Mpredicted

Average errors were calculated for First Order Kinetic Model, Modified Gompertz Model, and Logistic Function (Table 5). Maximum error was observed for First Order Kinetic Model in the case of all three organic cultures (Figures 8-10).

Table 5. Average Errors For the three cultures

\begin{tabular}{ccc}
\hline Average Error & Industrial Culture & Cow Dung \\
\hline First Order Kinetic Model & $7 \%$ & $43 \%$ \\
\hline Modified Gompertz Model & $4 \%$ & $16 \%$ \\
\hline Logistic Model & $4 \%$ & $6 \%$ \\
\hline
\end{tabular}

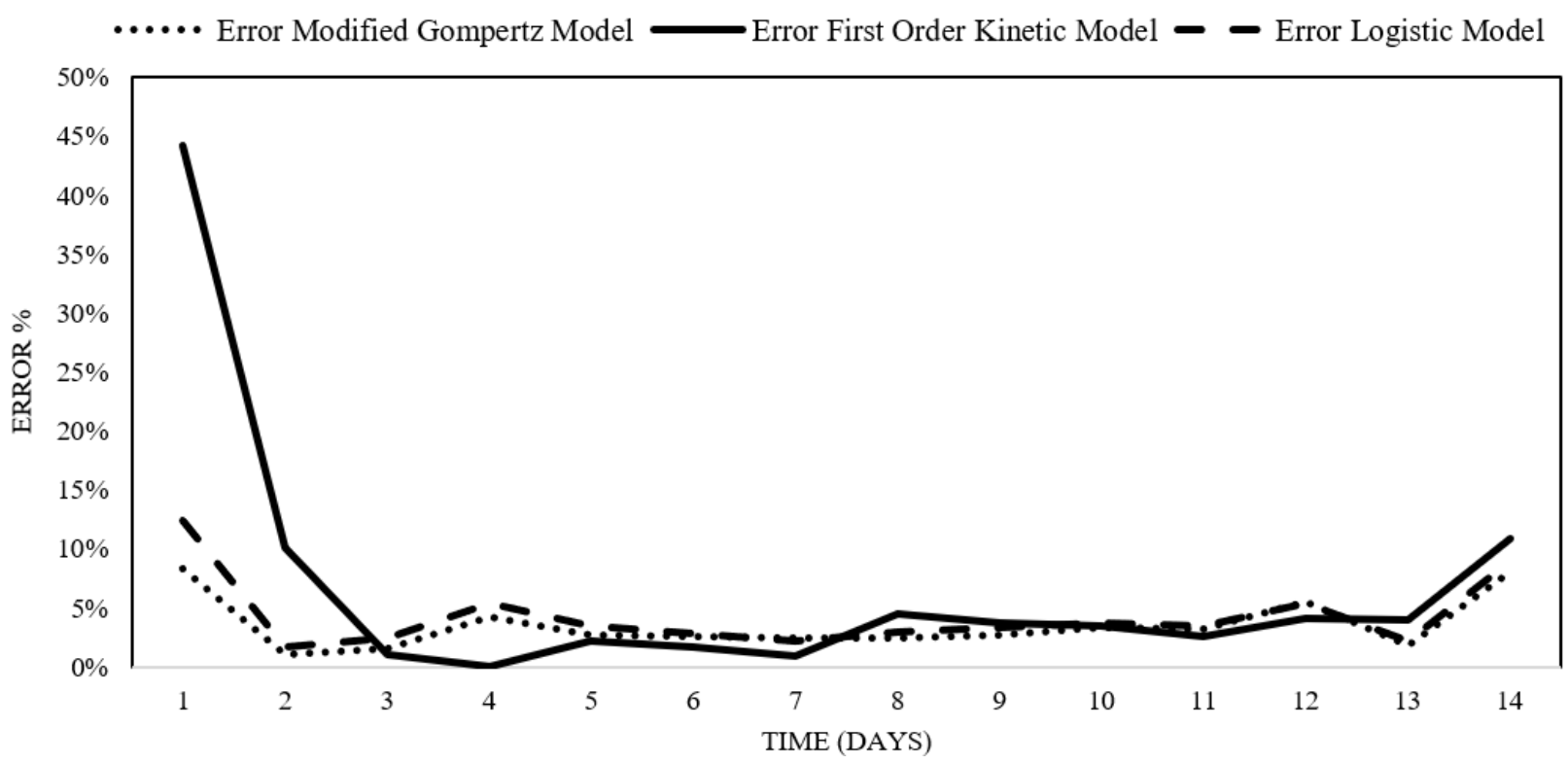

Figure 8. Error Comparisons for Industrial Culture using the three models 


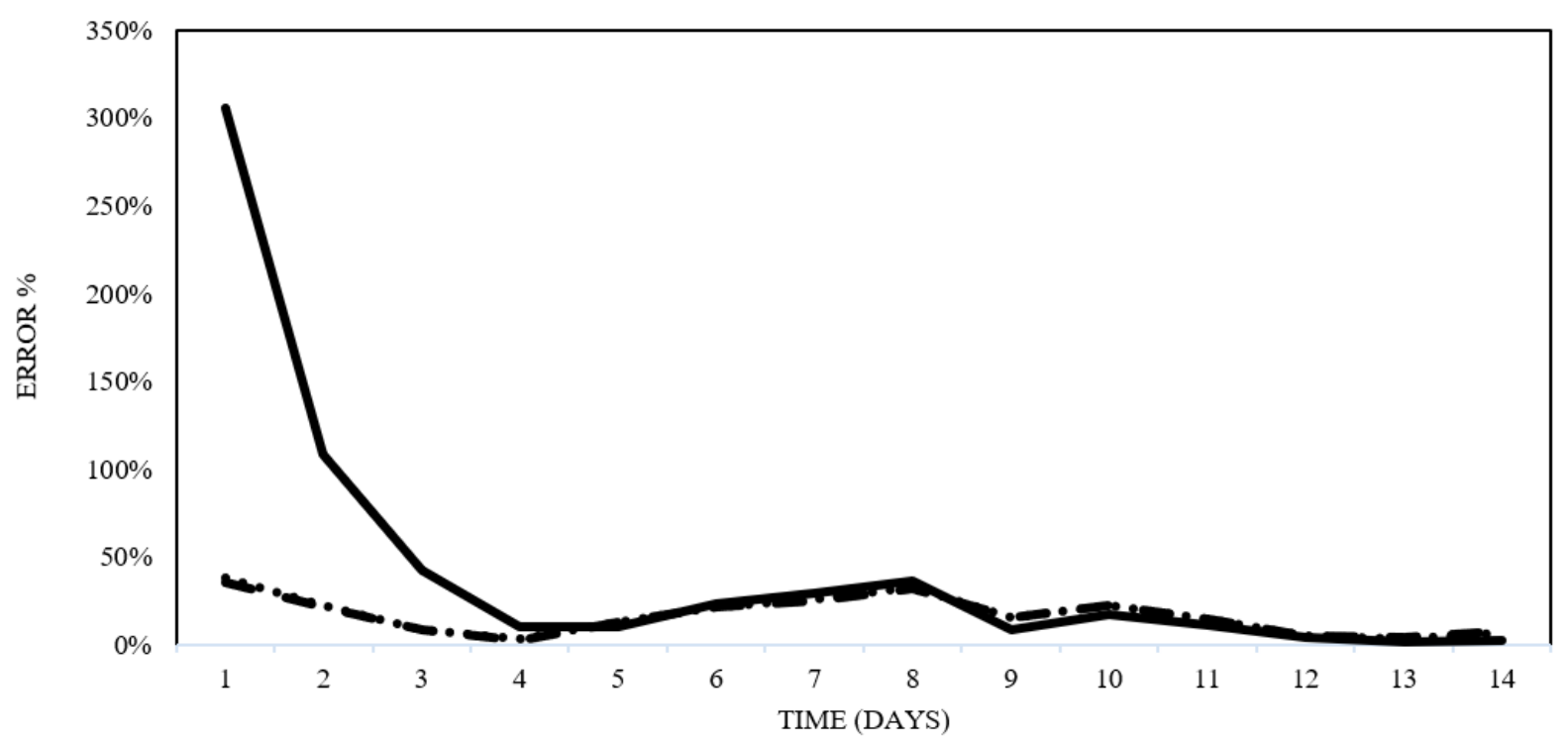

Figure 9. Error Comparisons for Cow Dung using the three models

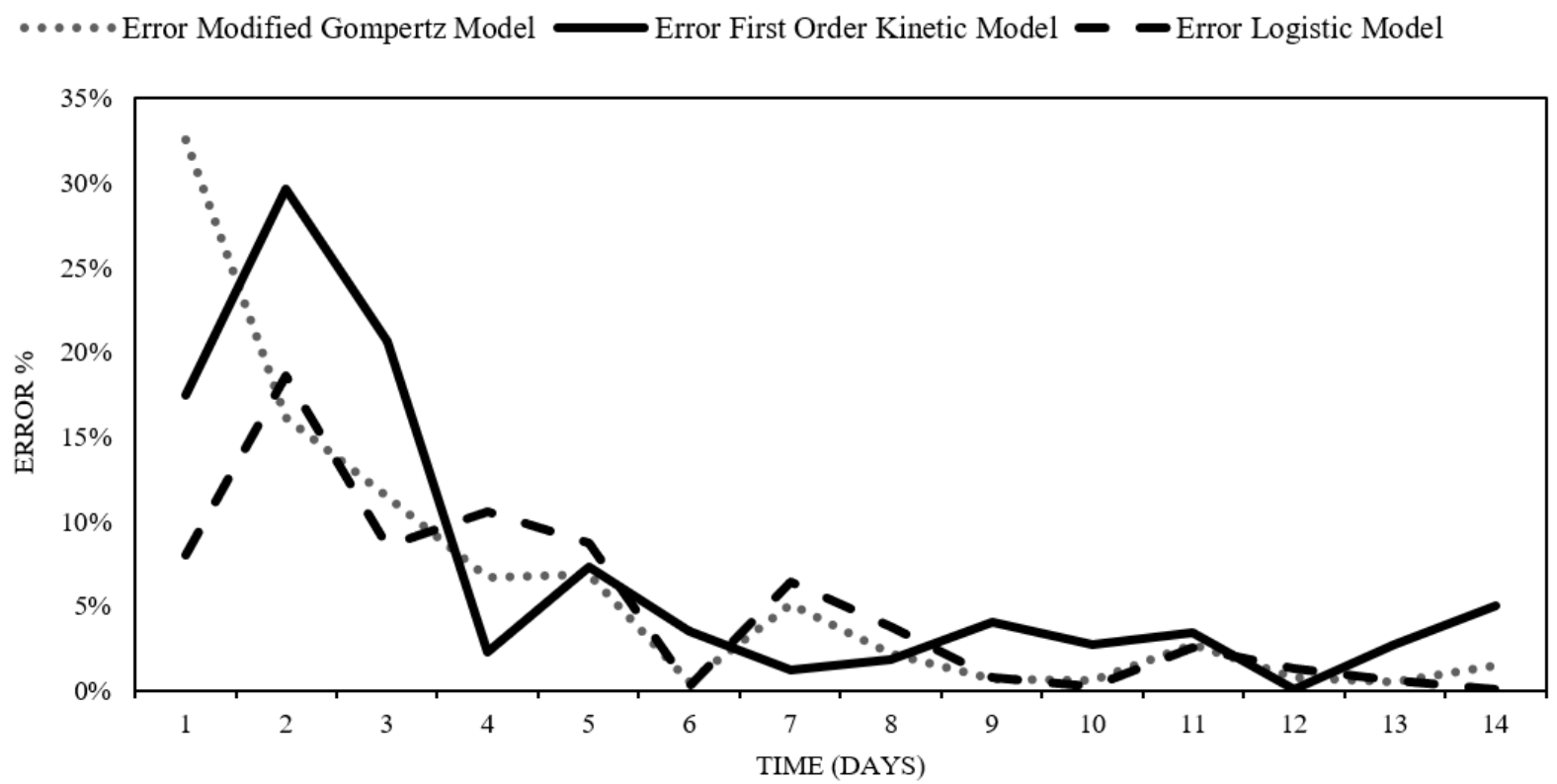

Figure 10. Error Comparisons for Horse Waste using the three models

\section{Error Comparison in Predictive Models Used}

From the data collected on modelling error, it is clear that the initial prediction of the First Order Kinetics model is highly erroneous with a maximum average error of $43 \%$, whereas its counterparts have a reasonable maximum error of $16 \%$ (Table 5). The Modified Gompertz Model and the Logistic Model closely resemble the experimental data and the results are well within the acceptable error range and hence these are appropriate for modelling biogas production, unlike the First Order Kinetic Model which produced higher errors and comparatively lower $\mathrm{R}^{2}$ values (Kafle and Kim, 2012). The high error in the First Order Kinetics Model may be attributed to the fact that it has two parameters whereas the Modified Gompertz Model, and the Logistic Model have three parameters, the third one being the duration of lag phase $(\lambda)$.

\section{CONCLUSION}

The volume of biogas produced from anaerobic digestion of HW culture was $35,366.03 \mathrm{~cm}^{3}$ over the 14-day cycle, which is $73.67 \%$ i.e. roughly three-fourths of the volume of biogas generated from IC and 3.85 times the volume generated by CD culture. Thus, the study indicates that the HW culture produces a satisfactory volume of biogas with satisfactory methane content in comparison to the proven IC, and largely outperforms the CD culture. It can be concluded that HW is a good alternative to CD in the case of organic cultures for biogas generation, especially for higher gas productivity for household or small-scale digesters. 
The Modified Gompertz model and the Logistic Model are better suited in terms of curve fitting as indicated by their Coefficients of Determination $\left(R^{2}\right)$, with a minimum value of 0.83 , unlike the First order Kinetic Model which yielded a poor value of 0.688 as its minimum value of $R^{2}$. Both the Modified Gompertz and Logistic Model were nearly similar in terms of curve fitting as indicated by the similar $R^{2}$ values- 0.83 and 0.99 for CD and HW respectively and in case of IC the resultant $R^{2}$ values are 0.98 and 0.97 for the two models. The Modified Gompertz Model was able to aptly predict the initial lag phase durations $(\lambda)$ for all the cultures studied. Therefore, it can be concluded that the Modified Gompertz Model was best suited to determine the Biogas Production Potential for all three cultures due to its better curve fitting and accurate lag phase predictability. Hence, Modified Gompertz Model can be employed in future studies to validate the experimental data for the biomass potential. For holistic understanding, more organic cultures can be explored for the production of biogas.

\section{REFERENCES}

Anukam, A., Mohammadi, A., Naqvi, M. and Granström, K. (2019). A review of the chemistry of anaerobic digestion: Methods of accelerating and optimizing process efficiency. Processes, 7(8), 504. https://doi.org/10.3390/pr7080504

Äüôú, Ö. (2003) 'Typical Characteristics of selected raw materials', (1), pp. 6-8. https://doi.org/10.16309/j.cnki.issn.10071776.2003.03.004

Awasthi, S. K., Joshi, R., Dhar, H., Verma, S., Awasthi, M. K., Varjani, S., Sarsaiya, S., Zhang, Z. and Kumar, S. (2018). Improving methane yield and quality via co-digestion of cow dung mixed with food waste. Bioresource technology, 251, 259-263. https://doi.org/10.1016/j.biortech.2017.12.063

Caruso, M. C., Braghieri, A., Capece, A., Napolitano, F., Romano, P., Galgano, F., Altieri, G. and Genovese, F. (2019). Recent updates on the use of agro-food waste for biogas production. Applied Sciences, 9(6), 1217. https://doi.org/10.3390/app9061217

Chakravarthi, J. (July 1997). Biogas and energy production from cattle waste. In IECEC-97 Proceedings of the Thirty-Second Intersociety Energy Conversion Engineering Conference (Cat. No. 97CH6203) (Vol. 1, pp. 648-651). IEEE.

Cucui, G., Ionescu, C. A., Goldbach, I. R., Coman, M. D. and Marin, E. L. M. (2018). Quantifying the economic effects of biogas installations for organic waste from agro-industrial sector. Sustainability, 10(7), 2582. https://doi.org/10.3390/su10072582

Donoso-Bravo, A., Pérez-Elvira, S. I. and Fdz-Polanco, F. (2010). Application of simplified models for anaerobic biodegradability tests. Evaluation of pre-treatment processes. Chemical Engineering Journal, 160(2), 607-614. https://doi.org/10.1016/j.cej.2010.03.082

Gerber, M. and Span, R. (2008). An analysis of available mathematical models for anaerobic digestion of organic substances for production of biogas. Proc. IGRC, Paris.

Ghatak, M. D. and Mahanta, P. (2014). Comparison of kinetic models for biogas production rate from saw dust. Carbon, $63,35$.

Hills, D. J. and Roberts, D. W. (1981). Anaerobic digestion of dairy manure and field crop residues. Agricultural Wastes, 3(3), 179189. https://doi.org/10.1016/0141-4607(81)90026-3

Horváth, I. S., Tabatabaei, M., Karimi, K. and Kumar, R. (2016). Recent updates on biogas production-a review. Biofuel Res. J, 10, 394-402. https://doi.org/10.18331/BRJ2016.3.2.4

Jain, S., Wolf, I. T. and Wah, T. Y. (2014). Anaerobic digestion of food waste using artificially cultured and natural anaerobes under Mesophilic conditions. J Mater Environ Sci, 5(6), 1709-1714.

Kafle, G. K. and Kim, S. H. (2012). Kinetic study of the anaerobic digestion of swine manure at mesophilic temperature: a lab scale batch operation. Journal of Biosystems Engineering, 37(4), 233-244. https://doi.org/10.5307/JBE.2012.37.4.233

Kalia, A. K. and Singh, S. P. (1998). Horse dung as a partial substitute for cattle dung for operating family-size biogas plants in a hilly region. Bioresource technology, 64(1), 63-66. https://doi.org/10.1016/S0960-8524(97)00159-4

Kumar, S., Smith, S. R., Fowler, G., Velis, C., Kumar, S. J., Arya, S., Rena, Kumar, R. and Cheeseman, C. (2017). Challenges and opportunities associated with waste management in India. Royal Society open science, 4(3), 160764. https://doi.org/10.1098/rsos.160764

Kusch, S., Oechsner, H. and Jungbluth, T. (2008). Biogas production with horse dung in solid-phase digestion systems. Bioresource technology, 99(5), 1280-1292. https://doi.org/10.1016/j.biortech.2007.02.008

Li, P., Li, W., Sun, M., Xu, X., Zhang, B. and Sun, Y. (2019). Evaluation of biochemical methane potential and kinetics on the anaerobic digestion of vegetable crop residues. Energies, 12(1), 26. https://doi.org/10.3390/en12010026

Manyi-Loh, C. E., Mamphweli, S. N., Meyer, E. L., Okoh, A. I., Makaka, G. and Simon, M. (2013). Microbial anaerobic digestion (biodigesters) as an approach to the decontamination of animal wastes in pollution control and the generation of renewable energy. International journal of environmental research and public health, 10(9), $4390-4417$. https://doi.org/10.3390/ijerph10094390

Mel, M., Ihsan, S. I. and Setyobudi, R. H. (2015). Process improvement of biogas production from anaerobic co-digestion of cow dung and corn husk. Procedia Chemistry, 14, 91-100. https://doi.org/10.1016/j.proche.2015.03.014

Nges, I. A. and Liu, J. (2010). Effects of solid retention time on anaerobic digestion of dewatered-sewage sludge in mesophilic and thermophilic conditions. Renewable Energy, 35(10), 2200-2206. https://doi.org/10.1016/j.renene.2010.02.022 
Okonkwo, U. C., Onokpite, E. and Onokwai, A. O. (2018). Comparative study of the optimal ratio of biogas production from various organic wastes and weeds for digester/restarted digester. Journal of King Saud University-Engineering Sciences, 30(2), $123-129$. https://doi.org/10.1016/j.jksues.2016.02.002

Parameswaran, P. and Rittmann, B. E. (2012). Feasibility of anaerobic co-digestion of pig waste and paper sludge. Bioresource technology, 124, 163-168. https://doi.org/10.1016/j.biortech.2012.07.116

Pavlostathis, S. G. and Giraldo-Gomez, E. (1991). Kinetics of anaerobic treatment: a critical review. Critical Reviews in Environmental Science and Technology, 21(5-6), 411-490. https://doi.org/10.1080/10643389109388424

Pramanik, S. K., Suja, F. B., Porhemmat, M. and Pramanik, B. K. (2019). Performance and kinetic model of a single-stage anaerobic digestion system operated at different successive operating stages for the treatment of food waste. Processes, 7(9), 600. https://doi.org/10.3390/pr7090600

Strömberg, S., Nistor, M. and Liu, J. (2014). Towards eliminating systematic errors caused by the experimental conditions in Biochemical Methane Potential (BMP) tests. Waste management, 34(11), $1939-1948$. https://doi.org/10.1016/j.wasman.2014.07.018

Tjørve, K. M. and Tjørve, E. (2017). The use of Gompertz models in growth analyses, and new Gompertz-model approach: An addition to the Unified-Richards family. PloS one, 12(6), e0178691. https://doi.org/10.1371/journal.pone.0178691

Ware, A. and Power, N. (2017). Modelling methane production kinetics of complex poultry slaughterhouse wastes using sigmoidal growth functions. Renewable Energy, 104, 50-59. https://doi.org/10.1016/j.renene.2016.11.045

Zwietering, M. H., Jongenburger, I., Rombouts, F. M. and van 't Riet, K. (1990). Modelling of the Bacterial Growth Curve, Appl.and Environ. Microbiol. 56 (6), 1875-1881. https://doi.org/10.1128/AEM.56.6.1875-1881.1990 